\title{
Epidemiology of spontaneous pneumothorax: gender-related differences
}

\author{
Antonio Bobbio, ${ }^{1}$ Agnès Dechartres, ${ }^{2,3,4}$ Samir Bouam, ${ }^{5}$ Diane Damotte, ${ }^{4,6}$ \\ Antoine Rabbat, ${ }^{7}$ Jean-François Régnard, ${ }^{1,4}$ Nicolas Roche, ${ }^{4,7}$ Marco Alifano ${ }^{1,4}$
}

For numbered affiliations see end of article.

\section{Correspondence to} Dr Antonio Bobbio, Service de Chirurgie Thoracique, Hôpitaux Universitaires Paris Centre, AP-HP-27, rue du Faubourg Saint Jacques, 75014 Paris, France; bobbioantonio@gmail.com; antonio.bobbio@cch.aphp.fr

Received 14 November 2014 Revised 24 March 2015 Accepted 27 March 2015 Published Online First 27 April 2015
CrossMark

\section{To cite: Bobbio $A$,}

Dechartres A, Bouam S,

et al. Thorax 2015;70:

653-658.

\section{ABSTRACT \\ Background Epidemiology of spontaneous}

pneumothorax has been scantily studied. We aimed to assess the incidence of spontaneous pneumothorax and describe patients' characteristics with respect to age, sex seasonal occurrence, primary or secondary character, surgical management and rehospitalisations on a largescale database.

Methods Data from all patients aged $\geq 14$ years and hospitalised with a diagnosis of non-traumatic pneumothorax in France from 2008 to 2011 were retrieved from the National Hospitalisation Database.

Results There were 59637 hospital stays corresponding to 42595 patients. Twenty-eight per cent of patients were rehospitalised at least once during the 4-year period. Annual rate of pneumothorax could be estimated at $22.7(95 \% \mathrm{Cl} 22.4$ to 23.0$)$ cases for 100000 habitants. The women to men ratio was 1:3.3. Mean age was significantly higher in women than in men $(41 \pm 19$ vs $37 \pm 19$ years, $p<0.0001)$. No seasonal variation was observed. A surgical procedure was performed in 14352 hospital stays (24\%). In the group of patients aged $<30$ years, there was no statistical difference between men and women with regard to type of pneumothorax (primary or secondary), type of hospitalisation unit (surgery vs medicine), treatment modality (surgery or not), intensive care unit (ICU) admission and hospital stay duration. Rehospitalisation was more frequent in women than in men $(56 \%$ vs $52 \%, p<0.0001)$. In the $30-49$ years age group, surgery and rehospitalisation were more frequent in women than in men (each, $p<0.001$ ). In the $50-64$ years age group, surgical procedures and rehospitalisations were more frequent in men than in women $(p=0.002$ and $p<0.0001$, respectively).

Conclusions Sex and age are determinant factors in the course of spontaneous pneumothorax.

\section{INTRODUCTION}

Pneumothorax is a frequent disease involving general practitioners, emergency room and intensive care unit (ICU) physicians, chest physicians, as well as general and thoracic surgeons. It is classified as traumatic or spontaneous. Spontaneous pneumothorax is termed primary in the absence of any obvious precipitating factor or secondary if an underlying pulmonary disease is present. ${ }^{1}$

Very few studies assessed the incidence of spontaneous pneumothorax on a large-scale basis. The first was performed 40 years ago in the USA as part of the Rochester Project. ${ }^{2}$ Subsequently, data from

\section{Key messages}

What is the key question?

- Are characteristics of idiopathic pneumothorax different with respect to sex and age?

What is the bottom line?

- Sex and age are strong determinants of the occurrence and course of spontaneous pneumothorax.

\section{Why read on?}

- The largest epidemiological study on spontaneous pneumothorax.

three national UK registries (General Practice Research Database, Hospital Episode Statistics and Data Science UK) were published in year $2000 .^{3}$ Interestingly, in this study, all cases of pneumothorax with or without hospital admission were evaluated. The incidence rate of primary and secondary pneumothorax was estimated at 24.0/ 100000 years in men and 9.8/100 000 years in women. We found no other large-scale study on the epidemiology of spontaneous pneumothorax, and further knowledge is derived from case series, with often conflicting results. ${ }^{4-9}$ A female to male ratio ranging from $1: 2$ to $1: 6$ has been suggested, but the incidence and distribution of pneumothorax with respect to age and sex are poorly known. ${ }^{2-6}$ A first peak of incidence occurs at 2025 years in men (relating to idiopathic pneumothorax) and a second peak is observed in both men and women aged more than 55 years, relating to underlying chronic lung diseases (mostly COPD). ${ }^{3}$ In women, the epidemiological study by Gupta et $a l^{3}$ found that the first peak is delayed at 30 34 years. The reasons for this gender-related difference are not known, but factors associated with idiopathic pneumothorax in men (active tobacco consumption and anthropometric characteristics) are less frequently found in women. ${ }^{10}{ }^{11}$ While some case series did not confirm these findings, ${ }^{4} 9$ recent prospective and retrospective surgical series also found a later occurrence of pneumothorax in women and showed that catamenial pneumothorax and endometriosis-related pneumothorax were responsible for approximately half of pneumothorax episodes in women of childbearing age referred for surgery. ${ }^{12-14}$ To date, no data on 
non-surgical cases of catamenial or endometriosis-related pneumothorax is available.

Some case series showed that changes in atmospheric pressure and some meteorological events (thunderstorm) were associated with clusters of pneumothorax, regardless of sex, raising the question of a possible seasonal character of the disease. ${ }^{15-17}$ However, the UK epidemiological study did not find such a seasonal distribution. ${ }^{3}$

In the present study, we aimed at investigating on a nationwide basis the characteristics, management and course of patients hospitalised with spontaneous pneumothorax. Specifically, analyses were designed to determine the incidence of this condition, age and gender distribution, type of pneumothorax (primary or secondary), proportion of patients undergoing surgery, length of hospital stay and number of hospitalisations, as well as the influence of age, gender and type of pneumothorax on these outcomes.

\section{METHODS}

Study design and database structure

The study is based on 2008-2011 exhaustive data from the 'Programme de Médicalisation des Systèmes d'Information' database (programme for medicalisation of information systems, PMSI) of the national healthcare system, which collects data on all hospital stays, regardless of duration, in French public and private hospitals. In addition to its administrative purpose (monitoring of hospital activity based on the diagnostic-related groups (DRGs) model to inform pricing and strategic decisions by payers and policy makers), the database is also used for epidemiological purposes in several areas. ${ }^{18-22}$ Data are collected on a real-time basis and analysed yearly and include the ciphered identification of the patient, the main diagnosis leading to the hospitalisation, associated comorbidities and hospitalrelated complications, as well as other administrative and medical information, including some treatment modalities. Diagnostic coding relies on the international classification of diseases (ICD, WHO) and follows its updates. Coding of medical and surgical procedures is based on the French 'Classification Commune des Actes Médicaux' (common classification of medical procedures, CCAM). The main diagnosis is allocated by treating clinicians in charge of the patients immediately after discharge.

\section{Retrieved data}

All stays with a discharge diagnosis of non-traumatic pneumothorax were retrieved. The data obtained from each stay included the age and sex of the patient, the primary or secondary nature of the pneumothorax, the type of hospital unit(s) in which the patient was hospitalised (medicine/surgery/ICU), the month of hospitalisation and the duration of hospital stay. All iterative hospitalisations of the same patients during the 4-year study period could be identified.

\section{Statistics}

Categorical data were described as numbers (\%) and continuous variables as mean (SD). Characteristics were compared (1) between men and women and (2) between idiopathic and secondary pneumothorax, using generalised estimating equation (GEE) to account for multiple hospitalisations of a given patient. For the comparison between male and female, we stratified analyses by age classes ( $\leq 30,31-50$ and $51-65$ years old). Finally, we assessed which characteristics were associated with length of stay and surgical treatment. For all tests, a $\mathrm{p}$ value (two-sided) $<0.05$ was considered statistically significant. In this exploratory study, we did not correct $\alpha$ risk for multiple testing.

\section{RESULTS}

In the national database, among more than 68 million hospitalisations, 60094 were associated with a main diagnosis of non-traumatic pneumothorax over the period January 2008December 2011. After excluding 436 hospitalisations related to patients aged less than 14 years and 21 with inadequate coding data, 59637 hospitalisations were analysed.

\section{Characteristics of patients}

The 59637 hospitalisations corresponded to 42595 patients. Mean age was $39 \pm 20$ years. A total of $32632(77 \%)$ were male, corresponding to a women to men ratio of $1: 3.3$. Pneumothorax was idiopathic in $85 \%$ of patients $(n=36563)$ and secondary in 15\%. A total of 12084 patients $(28 \%)$ had more than one pneumothorax-related hospital stay over the 4 -year period. There were 44815 hospital stays during the first 3 years, corresponding to 32618 patients. Out of these, 8653 $(26.5 \%)$ had a recurrence within 1 year of the first recorded episode.

\section{Distribution of hospitalisations over the 4-year period}

The annual number of hospitalisations for pneumothorax was stable over the study period, with between 14747 and 15170 hospital stays yearly. Thus, the annual rate of hospital stay for spontaneous pneumothorax in France (considering a French population of 65.7 million) could be estimated at 22.7 per 100000 (95\% CI 22.4 to 23.0 per 100 000). There was no significant monthly or seasonal variation of distribution: March, October and December accounted each for $9 \%$ of hospitalisations, the other months for $8 \%$, while $25 \%$ of the cases occurred in winter and spring, $24 \%$ in summer and $26 \%$ in the autumn (table 1). No significant difference in the seasonal distribution of hospitalisations was observed between men and women or between primary and secondary pneumothorax (data not shown).

\section{Characteristics of hospital management}

Overall, the median duration of hospital stay was 7 days. Hospitalisations occurred in a medical unit in $73 \%$ of cases and in a surgical unit in $27 \%$ of cases. In $27 \%$ of cases, the management involved intensive or intermediate care. A surgical procedure was performed during 14352 hospitalisations (24\%), mostly through thoracoscopy (76\%). The most commonly performed procedures were thoracoscopic resection of blebs with a pleural abrasion in $7529(52 \%)$ cases and a talc pleurodesis in $24 \%$ of cases (table 1). Surgery was associated with younger age (mean, 34 vs 39 years, $\mathrm{p}<0.0001$ ), secondary pneumothorax $(\mathrm{p}<0.0001)$ and ICU surveillance $(\mathrm{p}<0.0001)$. There was no difference in the type of surgical intervention (especially, thoracotomy vs thoracoscopy) with respect to the type of pneumothorax (data not shown).

\section{Differences between men and women}

Mean age was significantly higher in women than in men (41 \pm 19 vs $37 \pm 19$ years, $p<0.0001)$. Age distribution showed a different profile between sexes (figure 1), with a more marked peak in young men and a shift towards higher age in women. Secondary pneumothorax was more frequent in men than in women $(16 \%$ vs $13 \%, \mathrm{p}<0.0001)$. A surgical procedure was slightly more common in men than in women $(24 \%$ vs $23 \%$, $\mathrm{p}=0.02$ ) (table 2). Subgroup analysis showed that age was 
Table 1 Characteristics of hospitalisations for non-traumatic pneumothorax between 2008 and 2011 in France

\begin{tabular}{lr}
\hline Characteristics & $\mathrm{N}=59637$ \\
\hline Age (years), mean (SD) & $38(19)$ \\
Year, $\mathrm{n}(\%)$ & \\
2008 & $14747(25 \%)$ \\
2009 & $15170(25 \%)$ \\
2010 & $14898(25 \%)$ \\
2011 & $14822(25 \%)$ \\
Season, $\mathrm{n}(\%)$ & \\
Winter & $14927(25 \%)$ \\
Spring & $15101(25 \%)$ \\
$\quad$ Summer & $14442(24 \%)$ \\
$\quad$ Fall & $15167(26 \%)$ \\
Pneumothorax type & \\
$\quad$ Idiopathic & $50596(85 \%)$ \\
$\quad$ Secondary & $9041(15 \%)$ \\
Place of hospitalisation & \\
$\quad$ Surgical ward & $16236(27 \%)$ \\
$\quad$ Medical ward & $43401(73 \%)$ \\
Intensive or intermediate care unit & $16057(27 \%)$ \\
Surgical treatment & $\mathrm{n}=14352$ \\
$\quad$ Thoracoscopic blebs resection with partial pleural & $7529(52 \%)$ \\
resection or pleural abrasion & \\
Intrapleural instillation of irritant substance & $3431(23 \%)$ \\
Resection of bullae by thoracotomy & $2889(20 \%)$ \\
Others & $503(5 \%)$ \\
Hospitalisation duration, mean (SD) & $7.0(9.0)$ \\
\hline
\end{tabular}

higher in women with pneumothorax considered idiopathic as compared with men $(\mathrm{p}<0.0001)$, but lower in women with secondary pneumothorax $(\mathrm{p}<0.0001)$ (table 2$)$.
In patients aged less than 30 years $(\mathrm{N}=25$ 156), there was no statistical difference between men and women with regard to type of pneumothorax, type of hospitalisation unit (surgery vs medicine), treatment modality (surgery or not), ICU admission and duration of hospital stay (table 3). Rehospitalisation was more frequent in women than in men $(56 \%$ vs $52 \%, \mathrm{p}=0.001)$. Among patients aged $31-50$ years $(\mathrm{N}=15$ 906), there was a significantly higher rate of hospitalisation in a surgical unit in women than in men $(32 \%$ vs $29 \%, \mathrm{p}<0.0001)$ as well as a higher rate of surgical intervention $(28 \%$ vs $26 \%, \mathrm{p}=0.004)$. The risk of being hospitalised for pneumothorax more than once during the study period was also significantly greater in women $(54 \%$ vs $46 \%, \mathrm{p}<0.0001)$. In patients aged $50-65$ years $(\mathrm{N}=7774)$, secondary pneumothorax was significantly more frequent in men who were more frequently hospitalised in a surgical unit $(\mathrm{p}<0.0001)$ and underwent surgery more often $(20 \%$ vs $17 \%, \mathrm{p}<0.0001)$. Hospital stay was longer in men than in women (mean duration 10.1 (14.5) vs 9.5 (14.8) days) $(\mathrm{p}<0.0001)$, and rehospitalisations were also significantly more frequent in men $(45 \%$ vs $38 \%, \mathrm{p}<0.0001)$.

\section{Differences between idiopathic and secondary pneumothorax}

Mean age was higher in patients with secondary pneumothorax than in those with idiopathic pneumothorax $(53 \pm 20$ vs $35 \pm 18$, $\mathrm{p}<0.0001$ ) (table 4). The proportion of men was significantly higher for secondary than idiopathic pneumothorax $(80 \%$ vs $76 \%, \mathrm{p}<0.0001)$. In patients with secondary pneumothorax, a surgical procedure was more frequent $(33 \%$ vs $23 \%, \mathrm{p}<0.001)$ and, accordingly, more patients were hospitalised in a surgical unit and/or in an intensive or intermediate care unit $(36 \%$ vs $26 \%, \mathrm{p}<0.0001$ and $40 \%$ vs $25 \%, \mathrm{p}<0.0001$, respectively). Hospital stay was significantly longer (median duration 8 (5-14) vs 5 (3-7) days). In these patients, the risk of multiple hospitalisations for pneumothorax was higher $(52 \%$ vs $48 \%, \mathrm{p}<0.0001)$.

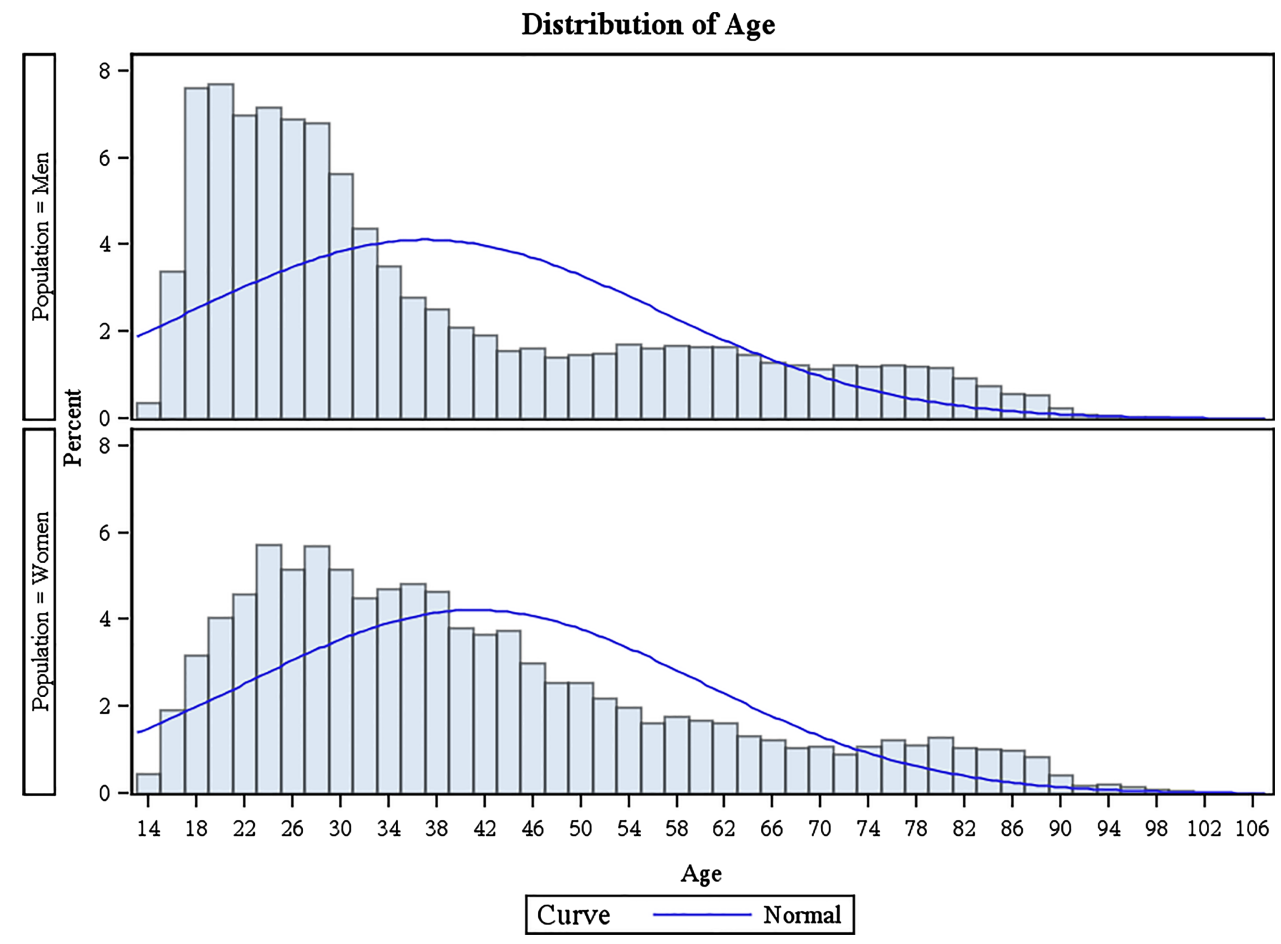

Figure 1 Distribution of hospitalisations for spontaneous pneumothorax with respect to sex and age class. Each bar represents a 2-year age class. 
Table 2 Comparison of hospitalisation characteristics between men and women

\begin{tabular}{|c|c|c|c|c|c|c|c|c|c|}
\hline \multirow[b]{2}{*}{ Characteristics } & \multicolumn{3}{|l|}{ Men } & \multicolumn{3}{|l|}{ Women } & \multicolumn{3}{|c|}{ p Value (men vs women) } \\
\hline & All & Idiopathic & Secondary & All & Idiopathic & Secondary & All & Idiopathic & Secondary \\
\hline $\mathrm{N}$ & 45711 & 38508 & 7203 & 13926 & 12088 & 1838 & & & \\
\hline Age (years), mean (SD) & $37(19)$ & $34(17)$ & $54(21)$ & $41(19)$ & $40(18)$ & $50(20)$ & 0.0001 & $<0.0001$ & $<0.0001$ \\
\hline Hospitalisation ward & & & & & & & 0.16 & 0.70 & 0.50 \\
\hline Surgical ward & $12501(27)$ & $9861(26)$ & $2640(37)$ & $3735(27)$ & $3077(25)$ & $658(36)$ & & & \\
\hline Medical ward & $33210(73)$ & $28647(74)$ & $4563(63)$ & $10191(73)$ & $9011(75)$ & $1180(64)$ & & & \\
\hline Intensive or intermediate care unit & $12249(27)$ & $9426(24)$ & $2823(39)$ & $3808(27)$ & $3030(25)$ & $778(42)$ & 0.23 & 0.21 & 0.02 \\
\hline Surgical treatment & $11094(24)$ & $8727(23)$ & $2367(33)$ & $3258(23)$ & $2671(22)$ & $587(32)$ & 0.02 & 0.14 & 0.46 \\
\hline Hospitalisation duration, days, mean (SD) & $6.9(8.8)$ & $5.9(6.7)$ & $12.2(14.5)$ & $7.2(9.7)$ & $6.4(8.5)$ & $12.1(14.5)$ & 0.007 & $<0.0001$ & 0.82 \\
\hline Rehospitalisation, n (\%) & $22413(49)$ & $18630(48)$ & $3783(53)$ & $6713(48)$ & $5802(48)$ & $911(50)$ & 0.21 & 0.58 & 0.06 \\
\hline
\end{tabular}

Characteristics associated with duration of hospital stay

Age $(\mathrm{p}<0.0001)$, secondary pneumothorax $(\mathrm{p}<0.0001)$, hospitalisation in a surgical unit $(\mathrm{p}<0.0001)$, intensive care or continuous surveillance $(p<0.0001)$ and surgical treatment $(p<0.0001)$ were associated with duration of hospital stay (data not shown).

Table 3 Comparison of hospitalisation characteristics between men and women stratified by age

\begin{tabular}{|c|c|c|c|}
\hline Characteristics & Men & Women & p Value \\
\hline Age $18-30$ years & $N=20669$ & $N=4487$ & \\
\hline Pneumothorax type & & & 0.95 \\
\hline Idiopathic & $19359(94 \%)$ & $4204(94 \%)$ & \\
\hline Secondary & $1310(6 \%)$ & $283(6 \%)$ & \\
\hline Place of hospitalisation & & & 0.33 \\
\hline Surgical ward & $6303(30 \%)$ & $1396(31 \%)$ & \\
\hline Medical ward & $14366(70 \%)$ & $3091(69 \%)$ & \\
\hline Intensive or intermediate care unit & $4773(23 \%)$ & $1045(23 \%)$ & 0.79 \\
\hline Surgical treatment & $5700(28 \%)$ & $1235(28 \%)$ & 0.93 \\
\hline Hospitalisation duration, days, mean (SD) & $5.4(4.5)$ & $5.5(5.3)$ & 0.06 \\
\hline Rehospitalisation, n (\%) & $10841(52 \%)$ & $2510(56 \%)$ & 0.001 \\
\hline Age $31-50$ years & $N=10620$ & $N=5286$ & \\
\hline Pneumothorax type & & & 0.26 \\
\hline Idiopathic & $9264(87 \%)$ & $4648(88 \%)$ & \\
\hline Secondary & $1356(13 \%)$ & $638(12 \%)$ & \\
\hline Place of hospitalisation & & & $<0.0001$ \\
\hline Surgical ward & $3071(29 \%)$ & $1677(32 \%)$ & \\
\hline Medical ward & $7549(71 \%)$ & $3609(68 \%)$ & \\
\hline Intensive or intermediate care unit & $2838(27 \%)$ & $1393(26 \%)$ & 0.63 \\
\hline Surgical treatment & $2745(26 \%)$ & $1464(28 \%)$ & 0.004 \\
\hline Hospitalisation duration, days, mean (SD) & $6.3(7.8)$ & $6.2(6.4)$ & 0.12 \\
\hline Rehospitalisation, n (\%) & $4907(46 \%)$ & $2835(54 \%)$ & $<0.0001$ \\
\hline Age $50-65$ years & $N=5821$ & $N=1953$ & \\
\hline Pneumothorax type & & & $<0.0001$ \\
\hline Idiopathic & $3778(65 \%)$ & $1508(77 \%)$ & \\
\hline Secondary & $2043(35 \%)$ & $445(23 \%)$ & \\
\hline Place of hospitalisation & & & 0.0001 \\
\hline Surgical ward & $1381(24 \%)$ & $382(20 \%)$ & \\
\hline Medical ward & $4440(76 \%)$ & $1571(80 \%)$ & \\
\hline Intensive or intermediate care unit & $1975(34 \%)$ & $627(32 \%)$ & 0.16 \\
\hline Surgical treatment & $1155(20 \%)$ & $326(17 \%)$ & $<0.0001$ \\
\hline Hospitalisation duration, days, mean (SD) & $10.1(14.5)$ & $9.5(14.8)$ & $<0.0001$ \\
\hline Rehospitalisation, $\mathrm{n}(\%)$ & $2616(45 \%)$ & $747(38 \%)$ & $<0.0001$ \\
\hline
\end{tabular}

\section{Characteristics associated with multiple hospitalisations}

When comparing the characteristics of the patients recorded at first hospital stay during the 4-year period, those who had more than one hospitalisation were younger $(35 \pm 18$ vs $40 \pm 20$ years, $\mathrm{p}<0.0001)$, underwent a surgical procedure more frequently $(18 \%$ vs $17 \%, \mathrm{p}<0.0001)$ and were more frequently hospitalised in a surgical unit $(21 \%$ vs $19 \%, \mathrm{p}<0.001)$.

\section{DISCUSSION}

This analysis of all hospitalisations for adult spontaneous pneumothorax recorded in an exhaustive nationwide database during a 4-year period provides unique data on the epidemiology and management of spontaneous pneumothorax at a population level. Major findings relate to the rather high annual incidence of hospitalisations (22.7/100 000), the lack of seasonality, the strong male predominance (sex ratio: 1:3.3), the younger age and earlier peak of incidence in men, the rate of surgical procedures (about a quarter of the patients) and the high proportion of patients with multiple hospitalisations for pneumothorax (28\%). An age-dependent influence of gender on disease's characteristics and outcomes was also demonstrated, suggesting that pneumothorax in men and women are largely different diseases. As expected, secondary pneumothorax also has specific characteristics from epidemiological (older age, greater male predominance), management (more frequent surgery) and outcomes (higher length of stay and number of hospitalisations) perspectives. This could, in part, explain some

Table 4 Comparison of hospitalisation characteristics between idiopathic and secondary pneumothorax

\begin{tabular}{|c|c|c|c|c|}
\hline Characteristics & $\begin{array}{l}\text { Overall } \\
\mathrm{N}=59637\end{array}$ & $\begin{array}{l}\text { Idiopathic } \\
\mathrm{N}=50596\end{array}$ & $\begin{array}{l}\text { Secondary } \\
\mathrm{N}=9041\end{array}$ & p Value \\
\hline Age (years), mean (SD) & 38 (19) & $35(18)$ & $53(20)$ & $<0.0001$ \\
\hline Sex, male, n (\%) & $45711(77 \%)$ & $38508(76 \%)$ & $7203(80 \%)$ & $<0.0001$ \\
\hline Place of hospitalisation & & & & $<0.0001$ \\
\hline Surgical ward & $16236(27 \%)$ & $12938(26 \%)$ & $3298(36 \%)$ & \\
\hline Medical ward & $43401(73 \%)$ & $37658(74 \%)$ & $5743(64 \%)$ & \\
\hline $\begin{array}{l}\text { Intensive or intermediate } \\
\text { care unit }\end{array}$ & $16057(27 \%)$ & $12456(25 \%)$ & $3601(40 \%)$ & $<0.0001$ \\
\hline Surgical treatment & $14352(24 \%)$ & $11398(23 \%)$ & $2954(33 \%)$ & $<0.0001$ \\
\hline $\begin{array}{l}\text { Hospitalisation duration, } \\
\text { days, median (Q1, Q3) }\end{array}$ & $7.0(9.0)$ & $6.1(7.2)$ & $12.2(14.5)$ & $<0.0001$ \\
\hline Rehospitalisations, n (\%) & $29126(49 \%)$ & $24432(48 \%)$ & $4694(52 \%)$ & $<0.0001$ \\
\hline
\end{tabular}


gender-related differences since secondary pneumothorax is more frequent in men. However, other factors might contribute.

\section{Strengths and limitations of the study}

The most obvious strength of this study relates to the high number of cases that could be analysed, permitted by the exhaustive nationwide character of the database with regard to hospitalisations. This allows determining whether findings from case series apply at a population level.

The lack of data on pneumothorax managed in the community could be considered as a study limitation. However, it should be pointed out that national recommendations for the management of spontaneous pneumothorax suggest hospital admission regardless of the character and extent of pneumothorax. A small percentage of asymptomatic patients with a first episode of idiopathic pneumothorax and a minimal apical $(<3 \mathrm{~cm})$ pneumothorax are managed on an out-patient basis, provided that (1) the pneumothorax does not aggravate after some hours of observation in the emergency department, (2) the patient lives close to hospital facilities and (3) the patient is not alone at home. ${ }^{23}$ These patients are not taken into account in this study, which may reduce the estimates of incidence and recurrence. However, they represent only a small fraction of the whole population of spontaneous pneumothorax patients. Other limitations relate to the nature and corresponding structure of the database. The lack of complete clinical data prevents from assessing in more detail the clinical factors associated with demographical features, management and outcomes. Similarly, assessment of recurrences was limited by the lack of data on both history of pneumothorax before and after the 4-year study period and the side of the pneumothorax. Finally, it should be acknowledged that the quality of coding might vary from one hospital to another.

\section{Incidence rates}

The annual rate of hospitalisation for non-traumatic pneumothorax is unknown so far in the majority of countries. In our study, the corresponding figure was 22.7 per 100000 . Taking into account rehospitalisations, this rate decreased to 16.2 per 100000 habitants. These rates are similar to those reported in the study of the Rochester programme in Olmsted County, Minnesota, which showed an age-corrected incidence of 13.7/ 100000 for men and 3.2/100 000 for women. ${ }^{4}$ Interestingly, in the UK study of about 22000 cases, the overall consulting rates for primary and secondary pneumothorax were 24.0/100 000 years in men and 9.8/100 000 years in women, whereas the hospital admission rates were 16.7/100 000 years and 5.8/100 000 years, respectively. ${ }^{3}$

We observed a lower incidence of secondary pneumothorax than in previous epidemiological studies. ${ }^{4}$ However, it should be pointed out that most of these studies involved much lower numbers of cases from limited numbers of centres (in the Rochester study, there were141 cases of spontaneous pneumothorax, of which 77 were considered idiopathic and 64 secondary). Thus, some selection, assessment or reporting biases cannot be excluded. In our study, we cannot exclude that, in some instances, underlying lung disease was not reported in medical records, but this is unlikely and therefore should not affect results. In addition, the amount paid to hospitals by the French National Health System is greater when associated diagnoses are present, which favours adequate reporting of comorbidities.

\section{Seasonality}

The seasonal character of pneumothorax remains a matter of debate. It has been previously reported that pneumothorax occurs in clusters and such clusters are thought to be related to changes in atmospheric pressure. ${ }^{15}$ Likewise, it has been suggested that some particular meteorological events (thunderstorms) are also associated with the occurrence of pneumothorax. ${ }^{16}$ On the other hand, a possible seasonal character could be explained by the recrudescence of respiratory infections in winter rather than changes in atmospheric pressure. ${ }^{16}$ In the present study, we did not find any seasonal variations in the occurrence of pneumothorax.

\section{Gender-related specificities}

We confirmed the marked predominance of spontaneous pneumothorax in men with a women to men ratio of 1:3.30. Age at hospitalisation was significantly higher in women, an already reported characteristics of spontaneous pneumothorax. ${ }^{3}$ Additionally, we were able to provide further insight in differences between men and women regarding age distribution (figure 1): in men, the first peak of incidence occurred before the age of 20 and the incidence progressively decreased until about 50 years of age, where it rapidly rose again. This typically reflects the peak of incidence of idiopathic pneumothorax observed in young men and the peak of secondary pneumothorax, mainly related to underlying chronic lung diseases (mostly COPD). Among women, the first peak appears to be delayed and incidence remains stable up to 40 years. Similar to men, a second peak is observed around 60 years (although to a lesser extent than in men), probably also due to COPD-related secondary pneumothorax. Thus, if the second peak of pneumothorax (beyond 55 years) probably shares the same characteristics in both genders, features of pneumothorax at younger age seem markedly different between men and women. Differences are particularly prominent in the 30-50 age group. In this category, women had a higher rate of surgery and rehospitalisation. Although data recorded in the database do not allow any firm conclusion, it can be hypothesised that a significant part of cases occurring in women of this age range relates to thoracic endometriosis syndrome (catamenial pneumothorax, endometriosisrelated or not and non-catamenial endometriosis-related pneumothorax). ${ }^{9}{ }^{14}$ Indeed, pathological studies have underlined that these gender-specific pneumothorax account for up to $40 \%$ of pneumothorax in women referred for surgery. ${ }^{14} 24$

\section{Management}

Video-assisted thoracoscopic apical resection with pleural abrasion is the more frequent procedure. Other techniques, including talc pleurodesis with thoracoscopic or thoracotomic apical resection, are less frequently implemented.

In conclusion, despite some limitations, this study brings important information on the epidemiology of spontaneous pneumothorax, including incidence, sex ratio, age distribution, as well as surgical procedures performed. Furthermore, this study outlines the differences in clinical presentation and course of spontaneous pneumothorax between men and women at different ages, which could reflect gender-related differences in the occurrence of secondary pneumothorax and gender-specific pathogenic mechanisms of spontaneous pneumothorax in younger patients. The present study highlights that these differences are relevant at a population level and might have implications for management strategies, both from diagnostic (endometriosis diagnostic workup) and therapeutic (decisions of surgery) perspectives. To better answer these questions, it would be useful to set nationwide exhaustive database registries centred on the clinical and pathological aspects of spontaneous pneumothorax. 


\section{Author affiliations}

${ }^{1}$ Service de Chirurgie Thoracique, Hôpitaux Universitaires Paris Centre, AP-HP, Paris, France

${ }^{2}$ Centre d'Epidémiologie Clinique, Hôpitaux Universitaires Paris Centre, AP-HP, Paris, France

${ }^{3}$ Inserm U1153, Paris, France

${ }^{4}$ Université Paris Descartes, PRES Sorbonne Paris Cité, Paris, France

${ }^{5}$ Direction Information Médicale, Hôpitaux Universitaires Paris Centre, AP-HP, Paris, France

${ }^{6}$ Service de Pathologie Hôpitaux Universitaires Paris Centre, AP-HP, Paris, France

${ }^{7}$ Service de Pneumologie, Hôpitaux Universitaires Paris Centre, AP-HP, Paris, France

Contributors $A B, S B$ and $A D$ conducted and are responsible for data analysis and drafting of the manuscript. DD, AR and J-FR contributed to the study design. NR contributed to data analysis and performed revision of the manuscript. MA was responsible for study conception and design and contributed to manuscript writing and revision.

Competing interests None declared.

Provenance and peer review Not commissioned; externally peer reviewed.

\section{REFERENCES}

1 Light RW, Lee RW. Pneumothorax, chylothorax, hemothorax and fibrothorax. In: Murray J, Nadel J, Mason R, et al., eds. Textbook of respiratory diseases. 5th edn. Philadelphia: Saunders Elsevier, 2010:1764-91.

2 Melton LJ, Hepper NG, Offord KP. Incidence of spontaneous pneumothorax in Olmsted County, Minnesota: 1950-1974. Am Rev Respir Dis 1979;120:1379-82.

3 Gupta D, Hansell A, Nichols T, et al. Epidemiology of pneumothorax in England. Thorax 2000;55:666-71.

4 Nakamura H, Konishiike J, Sugamura A, et al. Epidemiology of spontaneous pneumothorax in women. Chest 1986;89:378-82.

5 Weissberg D, Refaely Y. Pneumothorax: experience with 1,199 patients. Chest 2000;117:1279-85.

6 Primrose WR. Spontaneous pneumothorax: a retrospective review of aetiology, pathogenesis and management. Scott Med J 1984;29:15-20.

7 Schramel FM, Postmus PE, Vandeschueren RG. Current aspects of spontaneous pneumothorax. Eur Respir J 1997;10:1372-9.

8 Sahn SA, Heffner JE. Spontaneous pneumothorax. N Engl J Med 2000;342:868-74.
9 Sadikot RT, Greene T, Meadows K, et al. Recurrence of primary spontaneous pneumothorax. Thorax 1997;52:805-9.

10 Lippert HL, Lund 0 , Blegvad S, et al. Independent risk factors for cumulative recurrence rate after first spontaneous pneumothorax. Eur Respir J 1991;4:324-31.

11 Bense L, Eklund G, Wiman LG. Smoking and increased risk of contracting spontaneous pneumothorax. Chest 1987;92:1009-12.

12 Alifano M, Roth T, Broët SC, et al. Catamenial pneumothorax: a prospective study. Chest 2003;124:1004-8.

13 Alifano M, Jablonski C, Kadiri $\mathrm{H}$, et al. Catamenial and noncatamenial, endometriosis-related or nonendometriosis-related pneumothorax referred for surgery. Am J Respir Crit Care Med 2007;176:1048-53.

14 Legras A, Mansuet-Lupo A, Rousset-Jablonski C, et al. Pneumothorax in women of child-bearing age: an update classification based on clinical and pathologic findings. Chest 2014;145:354-60.

15 Bense L. Spontaneous pneumothorax related to falls in atmospheric pressure. Eur J Respir Dis 1984;65:544-6.

16 Alifano M, Forti Parri SN, Bonfanti B, et al. Atmospheric pressure influences the risk of pneumothorax: beware of the storm! Chest 2007;131:1877-82.

17 Scott GC, Berger R, Mckean HE. The role of atmospheric pressure variation in the development of spontaneous pneumothoraces. Am Rev Respir Dis 1989;139:659-62.

18 Olive F, Gomez F, Schott AM, et al. Critical analysis of French DRG based information system (PMSI) databases for the epidemiology of cancer: a longitudinal approach becomes possible. Rev Epidemiol Sante Publique 2011;59:53-8.

19 Holstein J, Farge D, Taright N, et al. [Hospital LOS, medical complexity and deprivation indicators]. Rev Epidemio/ Sante Publique 2009;57:205-11.

20 Bouam S, Gaucher S, Matrella F, et al. Increasing ambulatory surgery potential by non-medicalized accommodation: matched comparison of the 2011 national hospital activity data to 66 local stays. J Visc Surg 2014;151:263-8.

21 Lamarsalle L, Hunt B, Schauf $M$, et al. Evaluating the clinical and economic burden of healthcare-associated infections during hospitalization for surgery in France. Epidemiol Infect 2013;141:2473-82.

22 De Peretti C, Nicolau J, Tuppin P, et al. Acute and post-acute hospitalizations for stroke in France: recent improvements (2007-2009). Presse Med 2012;41:491-503.

23 Rabbat $A$, Lemarié $E$, Fraticelli $A$, et al. Pneumothorax spontané primitif. In: Lemarié $\mathrm{E}$, ed. La pneumologie fondée sur les épreuves. Paris: Marguax Orange, 2013:107-28.

24 Alifano M, Legras A, Rousset-Jablonski C, et al. Pneumothorax recurrence after surgery in women: clinicopathologic characteristics and management. Ann Thorac Surg 2011;92:322-6. 